Acta Cryst. (2002). A58 (Supplement), C141

\section{EFFECT OF SIDE CHAIN FUNCTIONAL GROUPS ON INCLUSION ABILITIES OF CHOLIC ACID \\ N. Yoswathananont ${ }^{1}$ K. Nakano ${ }^{2}$ K. Sada ${ }^{1}$ M. Miyata}

${ }^{1}$ Graduate School of Engineering, Osaka University Department of Material And Life Science 2-1 Yamadaoka, Suita OSAKA 565-0871 JAPAN ${ }^{2}$ Nagoya Municipal Industrial Research Institute, Atsuta-ku, Nagoya 456-0058, JAPAN

Inclusion compounds of cholic acid (CA) and its derivatives have been systematically investigated. Substitution of a carboxylic acid group by other functional groups at the steroidal side chain gives a wide variety of CA derivatives. For example, $\mathrm{CA}$ derivatives with amide and ester side chains are called cholamide (CAM) and methyl cholate (MC), respectively. Their inclusion crystals have been obtained by recrystallization from various organic compounds. It was found that CAM included various alcoholic guests, while CA did only limited alcohols. X-ray diffraction studies made clear that CAM forms a similar bilayer structure to $\mathrm{CA}$, indicating that both the hosts form the robust motif. In the case of MC, only small polar guests such as alcohols and nitriles are found to be included. This result indicates that the number of hydrogen bond donor at the side chains play an important role for the inclusion abilities of bile acids. Moreover, we demonstrate that PCcavity, volume ratio of guest molecules to the host cavities, is a useful parameter for estimating the steric size fit between host cavities and guest molecules as well as prediction of isomerization of the host framework and/or change of the host-guest ratios.

\section{Keywords: CHOLIC ACID PCCAVITY INCLUSION COMPOUND}

Acta Cryst. (2002). A58 (Supplement), C141

\section{FAST-ION CONDUCTION IN AN UNUSUAL THREE-DIMENSIONAL COORDINATION POLYMER CONTAINING NANO-SIZED CHANNELS}

$\underline{\text { X. Solans }}{ }^{1}$ M.C. Munoz ${ }^{2}$ A.B. Gaspar ${ }^{3}$ P. Demont ${ }^{4}$ A. Bousseksou ${ }^{5}$ J.A. Real ${ }^{3}$ ${ }^{1}$ University of Barcelona Crystallography Marti I Franques S/n BARCELONA E-08028 SPAIN

${ }^{2}$ Departament de Fisica Aplicada, Universitat Politecnica de Valencia. Spain ${ }^{3}$ Departament de Quimica Inorganica, Universitat de Valencia. Spain ${ }^{4}$ Laboratoire de Physique des Polymeres CIRIMAT, Touluse, France ${ }^{5}$ Laboratoire de Chimie de Coordination du CNRS, France

Crystal structure of $\mathrm{C}_{144} \mathrm{H}_{90} \mathrm{Cl}_{18} \mathrm{Fe}_{4} \mathrm{~N}_{24} \mathrm{Na}_{10} \mathrm{O}_{109}$ is shown. Intensities were collected with a MAR345 image plate detector. Crystal data: cubic, space group Pm-3n (no 223), a = 23.6270(10) $\AA \mathrm{V}=13189.42 \AA^{3}, \mathrm{Z}=2, \rho_{\text {calcd }}=$ $1.236 \mathrm{~g} \mathrm{~cm}^{-3}, 2387$ reflections observed $(\mathrm{I}>2 \sigma(\mathrm{I})) ; \mathrm{R}_{1}=0.0656, \mathrm{wR}_{2}=$ 0.1688 . The structure consists of a cationic polymeric framework of $[[\mathrm{Fe}(1)$ $\left.\sim]_{4} \mathrm{Na}_{3}\right]^{11+}(1=1,10$-phenanthroline-5,6-dione $)$. The holes defined by the porous network are loaded with sodium and perchlorate guest ions organized in such a way that 'naked' $\left[\mathrm{Na}^{+}\right]_{8}$ units, with a half occupation factor, are confined in cavities made up of $\mathrm{ClO}_{4}^{-}$counter-ions. The occurrence of vacant sites permits high conductivity even at low temperatures. The void defined by $\left\{[\mathrm{Fe}(1) \sim]_{4} \mathrm{Na}_{3}\right\}^{11+}$ corresponds to $60.4 \%$ of the total unit cell volume. The crystal structure gathers three singularities: (i) the charge distribution in the unit cell allows the occurrence of a cubic cluster of $\mathrm{Na}$ ions with half occupancy (this means that the number of available position is double regarding the number of $\mathrm{Na}$ atoms; (ii) the holes and $\mathrm{Na}$ atoms are uniformly and randomly distributed in the crystal, and (iii) the lack of coordination for the vacant site $\mathrm{Na}$ ions. The two last features are connected in many solids with low activation energy for ion diffusion and fast ion conductivity. This was confirmed by means of a.c. impedance spectroscopy measurements. They revealed an Arrhenius behaviour with a small departure at high temperature and an activation energy $E_{a}=1.4 \mathrm{~kJ} \mathrm{~mol}^{-1}$.

\section{Keywords: FAST-ION CONDUCTOR INORGANIC STRUCTURE} NANO-SIZED CHANELS
Acta Cryst. (2002). A58 (Supplement), C141

\section{INTERPRETING STRUCTURAL MOTIFS OF MOLECULAR MATERIALS BY WAY OF CRYSTAL STRUCTURE DETERMINATION DIRECTLY FROM POWDER DIFFRACTION DATA}

E.Y. Cheung K.D.M. Harris R.L. Johnston G.W. Turner S. Habershon A. Jove

University of Birmigham School of Chemical Sciences Edgbaston BIRMINGHAM B15 2TT UK

The aim of the direct-space strategy in structure solution from powder diffraction data is to generate crystal structures independently of the diffraction data and to assess the correctness of each trial structure by comparison of its simulated powder pattern with the experimental pattern [1]. A direct-space search is essentially a global optimization problem, for which the use of genetic algorithms (ga) are appropriate. Genetic algorithms are optimization methods founded upon the principles of evolution, and engaging the functions of mating, mutation, and natural selection towards the improvement of the fitness of the members of a population. The structures of complex molecular crystals from a wide range of fields have been solved using our genetic algorithm method [2], including examples from within chemistry, materials science, and structural biology [3]. Rationalization of these crystal structures offers insight and enables understanding into the structural motifs and properties of solids for which the growth of single crystals are either intractable, or undesirable [4]. Looking ahead to the future, improvements to such optimization techniques will result in increasingly complex problems being determined directly from powder diffraction data, enabling the further understanding of structure-property relationships in molecular solids.

References

[1] K.D.M. Harris, M. Tremayne, P. Lightfoot, P.G. Bruce, J. Am. Chem. Soc., 116, 3543 (1994)

[2] B.M. Kariuki, H. Serrano-Gonzalez, R.L. Johnston, K.D.M. Harris, Chem. Phys. Lett., 280, 189 (1997).

[3] K.D.M. Harris, M. Tremayne, B.M. Kariuki, Angew. Chem., Int. Ed. Engl., 40, 1626 (2001)

[4] E.Y. Cheung, E.E. McCabe, K.D.M. Harris, R.L. Johnston, E. Tedesco, K.M.P. Raja, P. Balaram, Angew. Chem., Int. Ed. Engl., 41,494 (2002).

Keywords: POWDER DIFFRACTION GENETIC ALGORITHM DIRECT SPACE

\section{Acta Cryst. (2002). A58 (Supplement), C141}

\section{ATOMIC DISPLACEMENT PARAMETERS, NORMAL MODE} ANALYSIS AND BOND LENGTH CORRECTION

T. Luethi Nyffeler ${ }^{1}$ C. Jelsch ${ }^{2}$ K. Ogawa ${ }^{3}$ H.-B. Buergi ${ }^{1}$

${ }^{1}$ Laboratorium Fuer Chem. Und Mineralog. Kristallographie Freiestrasse 3 BERN 3012 SWITZERLAND ${ }^{2}$ Laboratoire de Cristallographie et Modelisation des Materiaux Mineraux et Biologiques, Universite Henri Poincare, F-54506 Vandoeuvre-les-Nancy ${ }^{3}$ Departement of Chemistry of the University of Tokyo, Komaba, Meguro-ku, Tokyo, 153 Japan

In crystal structure analysis curvilinear vibration trajectories resulting from molecular and internal rotations are modelled by atomic displacement parameters (ADPs) implying linear displacements. The concomitant shift of atomic positions towards the rotation axes shortens interatomic distances. Some centrosymmetric (E)-stilbene derivatives provide an unusual example of this effect: the central $\mathrm{C}=\mathrm{C}$ double bond shortens substantially with increasing temperature, even after refinement with a multipolar atom model using MOPRO [1]. The shortening can not be due to molecular libration [2]. We have analyzed ADPs determined in the temperature range from 16 to $233.5 \mathrm{~K}$ for low frequency vibrations using a recently developed model of local normal modes [3]. Beside the librations and translations two deformation modes with frequencies below $100 \mathrm{~cm}-1$ were found: a crankshaft motion of the central $\mathrm{HC}=\mathrm{CH}$ - fragment and an in plane bending motion. The former is responsible for the apparent shortening of the ethylene bond distance. Normal modes of the isolated molecule were also calculated by density functional methods for comparison. The crankshaft frequency is found to be higher than that from ADPs and two additional low frequency deformation modes were obtained. The differences between the condensed and gaseous state are not yet understood.

References

[1] B. Guillot, L. Viry, R. Guillot, C. Lecomte \& C. Jelsch, J. Appl.Cryst. (2001), 34, 214

[2] K. Ogawa, T. Sano, S. Yoshimura, Y. Takeuchi and K. Toriumi, J. of the Am. Chem. Soc., (1992), 114, 1041

[3] H.B. Bürgi and S.C. Capelli, Acta Cryst. A, (2000), A56, 403

Keywords: ATOMIC DISPLACEMENT PARAMETERS BOND LENGTH CORRECTION E-STILBENE DERIVATIVES 